10-1996

\title{
Basics of research (Part 8): Unique aspects of nursing research
}

Cheryl Thompson

University of Nebraska Medical Center, cbthompson@unmc.edu

Cheryl J. Erler

Purdue University

Tell us how you used this information in this short survey.

Follow this and additional works at: https://digitalcommons.unmc.edu/con_articles

Part of the Nursing Commons

\section{Recommended Citation}

Thompson, Cheryl and Erler, Cheryl J., "Basics of research (Part 8): Unique aspects of nursing research" (1996). Journal Articles: College of Nursing. 20.

https://digitalcommons.unmc.edu/con_articles/20

This Article is brought to you for free and open access by the College of Nursing at DigitalCommons@UNMC. It has been accepted for inclusion in Journal Articles: College of Nursing by an authorized administrator of DigitalCommons@UNMC.For more information, please contact digitalcommons@unmc.edu. 


\title{
Basics of Research (Part 8): Unique Aspects of Nursing Research
}

\author{
Cheryl Bagley Thompson, PhD, RN, CS, ${ }^{1}$ Cheryl J. Erler, RN, MS²
}

1. University of Utah College of Nursing, Salt Lake City, Utah

2. School of Nursing, Furdue University, West Lafayette, Ind

Key Words: research, nursing research

Address for correspondence and reprints: Cheryl Bagley Thompson, PhD, RN, CS, University of Utah College of Nursing, $25 \mathrm{~S}$. Medical Drive, Salt Lake City, UT 84112.

Copyright 1996 by the Air Medical Journal Associates.

$1067-991 \times / 96 / \$ 5.00+0$

Reprint No. 74/1/77555
The best health care is provided when the actions of the provider are based on sound scientific principles (e.g., oxygen dissociation curve) or quality research findings (normal saline solution is sufficient to maintain vascular catheter patency). ${ }^{1}$ This relationship is as true for care provided during transport as for other types of health care. Consequently, clinical practice in the transport environment also must be based on sound scientific principles and quality research whenever possible.

Parts one through seven of the Basics of Research Series have provided knowledge regarding the research processes applicable to all facets of care and all disciplines involved in patient care during transport. Why then dedicate an entire article installment to nursing research? The answer to the question lies in the fact that nursing research may be perceived as being "different" from other kinds of research. To counter this misperception the authors will first discuss what nursing research is and ways in which nursing research is the same as all other research, as well as ways in which nursing research differs from the research of other disciplines. The authors also wish to dispel any misperceptions that nursing research is less rigorous or involves less quality control than research initiated by individuals of other disciplines.

The second area to be addressed will be questions and issues addressed by nursing research in comparison with other types of research. Previous studies will be used as examples of nursing research within the transport environment. Third, the issue of collaborative research will be discussed. Some of the strongest clinical research results when individuals from multiple disciplines collaborate to plan and implement patient-centered research studies.

Final sections will explore both sources of research support and research usc. Quality research depends on adequate knowledge of the research process and adequate funding to support personnel and equipment costs. Resources for both types of support will be provided. In addition, the need for translating research findings into actual patient care processes will be discussed in a section on research use.

\section{Nursing Research}

Research is the process of trying to answer questions by the application of scientific principles. Researchers may study individuals, animals, vegetation, inanimate objects, or situations. Situations may include human, animal, or physical interactions. Research questions range from simple description through the complex process of determining causality.

Nursing is defined as "the diagnosis and treatment of human response to actual or potential health problems." ${ }^{2}$ Consequently, a nurse researcher is usually interested in areas in which he or she can directly or indirectly affect the human response to actual or potential 
health problems. During air transport, nursing care is directed at the patient's response (hypoxemia, hypovolemia, etc.) to their injury or illness. Thus the focus of nursing research is not limited to a specific type of question, methodology, or subject population. Because of the overlap of disciplines within the health sciences, research questions asked by nurses also may have relevance for physicians, respiratory therapists, paramedics, and other health care providers. In addition, nurse researchers also may be interested in issues of the nature of the discipline of nursing.

From a methodologic standpoint, nursing research does not differ from research in other disciplines. For example, the first scven articles in this scrics apply equally as well to nursing research as to medical research. Nurses adhere to the same standards for conducting sound scientific investigations. For example, a nurse investigating the effect of two different approaches to minimizing pain during patient transfer would need to define the question, search the literature, identify an appropriate target population, design a methodologically sound study, use appropriate statistics, and adhere to acknowledged research standards.

Nursing research may not be as common for research questions related to transport as for other areas such as critical care nursing. The rationale for this statement is not that nursing research is inappropriate for transport-related issues but because the majority of nurses working in transport do not have extensive experience or education in the research process. As transport nurses grow in knowledge and experience, the amount of research should increase.

One of the apparent differences in nursing research that colleagues from other disciplines identify is the obsession of nurses with a theoretical framework or "nursing theory." Why do nurses need a theoretic framework when other disciplines seem to get along nicely without one? The reasons for this apparent difference evolve from two separate factors.

The first is that medicine, in contrast to nursing, has relied to a great extent on physiology as the theoretic framework for medical research. Because most medical research uses a physiologic theoretic framework, the theoretic framework often is assumed rather than stated in the final report. Consequently, the fact that a theoretic framework is being used may have been forgotten. For example, a study of intravenous fluid replacement in penetrating trauma may not state that the theoretic framework being used is that of human physiology. ${ }^{3}$ However, the known physiologic principles of blood circulation and cellular oxygenation did guide the selection of outcome variables and helped to explain the relationships noted in the data in the study by Bickell et al. ${ }^{3}$ The theoretic framework was essential to the study but remains hidden because the author did not draw attention to the underlying phlysiologic framework.

Another reason for the differences in theoretic frameworks is that nursing has evolved from a diverse theoretic background. Because of the holistic nature of nursing practice, nurses use theories from physiology, psychology, education, pharmacology, economics, sociology, and many others. Because a reader cannot assume that a nursing study used a physiologic theoretic framework, the framework must be described. In addition, many psychologic, educational, and other theories are not as widely accepted or understood outside of their parent field. Consequently, an explanation of the selected framework is essential to understanding the study report.

The use of a wide range of theories by nurses also has been promoted because nurses have obtained their research education from a variety of disciplines. Nurse researchers acquiring doctorates from academic areas such as physiology, sociology, psychology, and education may apply the theories and research methods from these disciplines to their research. In addition, nurse researchers may either develop and test their own theoretic framework or use the theoretic framework of another nursing scholar to guide their research.

A second reason that nursing research may appear to be different is because the questions that nurses ask (to be discussed later) may require different scientific methods than questions posed by other disciplines. Most areas of scientific inquiry start by asking questions of description and only later proceed to questions requiring more sophisticated experimental methods. For cxample, bc- cause nursing treats a patient's response to an injury or illness, a nurse may want to know what the experience of being transported for an injury is like for the patient. If patients state that their stress level is extremely elevated just by the fact that they will be riding in a helicopter, a dangerous form of transportation in their mind, the nurse may be able to develop an intervention that would reduce patient stress. By first recording descriptions of a patient's experiences, the nurse may be able to develop hypotheses that more directly address the problems as perceived by the patient. Once an intervention for the identified problem is developed, a randomized clinical trial could be used to evaluate the intervention.

Individuals not familiar with the nature of nursing research may criticize nursing research as not being rigorous because a descriptive method (either quantitative or qualitative) rather than an experimental method is being used in a particular study. However, a descriptive study is often the most appropriate way to answer the question being asked. With descriptive research, the variables important to decreasing patient stress (and ultimately improving patient outcome) during transport can be identified and subsequent experimental research improved.

Research methods may be unfamiliar or uncommon. However, descriptive methods are still held to appropriate standards, which are not necessarily the same as for experimental research. In addition, the reviewer must learn to recognize when descriptive methods are needed and when experimental methods are more appropriate. The use of descriptive techniques for variables that have been heavily investigated is just as inappropriate as trying to use experimental techniques when little is known of the variables under investigation. As demonstrated by Schwartz and Jacobs, ${ }^{4}$ all researchers concerned with patient transport must begin to build on available descriptive studies to advance knowledge related to patient transport.

Nursing research may encounter specific challenges because of the applied nature of the research and the uncontrolled clinical variables and environment. A bench researcher who uses test tubes, micc, and microscopic slides does 
not need to deal with subject consent. Randomization is easier if the mice or other specimens can be identified in whole before the start of the study. Nursing is not unique, however, as all transport research involves environmental challenges. Problems with conducting research concurrently with delivering patient care, randomizing subjects to groups, and controlling for extraneous variables within the sample must all be recognized as problems by the researcher. The problems must be appropriately accounted for in the research report and the author's conclusions. However, readers must not automatically dismiss as valueless research that encounters such problems. A subsequent issue in this scries will address methodologic problems accompanying clinical research in more depth.

\section{Nursing Research Topics}

Nurse researchers conduct many types of studies including bench research, 5 qualitative explorations of patient issues, ${ }^{6}$ and randomized controlled clinical trials. ${ }^{7}$ The only limitation with the type of research is that the researcher must be qualified to use the methodology selected for the study.

\section{Historical Efforts}

Nurses have been involved in research of transport-related topics since the $1980 \mathrm{~s} .{ }^{8-12}$ Early efforts were multidisciplinary, but slowly a body of nursing research with relevance to patient transport is being established independently by nurses in addition to the continuation of collaborative research. ${ }^{13-23}$

Nursing topics have included patient, environment, and personnel issues. Specific topics include among others, use of technology for patient care in the transport environment, flight nurse physical requircments, quality assurance, and family educational needs. The research conducted by nursing is descriptive for the most part. However, this is no different from most of the research related to air transport, regardless of the theoretic orientation.

\section{Priorities}

'The wide range of topics that has been explored by nurses is not without difficulties. The number of researchers is linited so that the wide range of topics limits the number working in one specific area. Scientific knowledge would accumulate faster if researchers built more on the work of others or followed a consistent line of inquiry throughout their career. For example, in the area of patient education. Johnson ${ }^{24-26}$ applied psychologic theories related to patient coping to nursing educational practices. In total Johnson's work has found that concrete sensory information is more beneficial to patients than other types of education. As a result much of nursing practice for helping patient's prepare for surgery, colonoscopy, and the like is directed by the research work of Johnson. Patients transport by air or ground may benefit from knowledge gained by extending Johnson's work to the transport environment.

A wide diversity of research also affects funding availability. If many different topics are explored, the funds available must be widely distributed. Consequently, less progress can be made in a single area of knowledge development. A method is needed to determine what studies have the potential for the greatest impact on nursing knowledge, particularly for patient care during transport. For example, funding five studies that all address pain management during transport may facilitate further progress in developing effective interventions than will funding one study on pain and four others on pressure sore development, suctioning technique, fluid resuscitation, and CPR technique.

The problems of research diversity is not unique to the transport environment and have been recognized as present in most areas of nursing practice. As a consequence, national organizations have sought to develop research priorities. ${ }^{27}$ This process was undertaken for air transport by Erler and Thompson ${ }^{15}$ who surveycd National Flight Nurse $\Lambda$ ssociation members using a Delphi technique to determine which research areas were most valued by flight nurses. Hopefully by identifying research priorities of $\mathrm{Na}$ tional Flight Nurses Association members, researchers and funding agencies will concentrate their efforts. The priorities identified were related to transport team composition, education, and mode of transport; patient outcomes; costs; advanced airway lechniques; and impact of health care reform.

\section{Collaborative Research}

Although nursing research relates to nursing questions, this statement does not imply that any given research area must be either nursing research or some other type of research. Many disciplines share interests in similar areas of scientific inquiry. For example, both physicians and nurses have investigated patient intubation. 21,28

In addition, many health care questions are multidisciplinary in nature and can best be studied by a team which consists of individuals from nursing, medicine, respiralory care, psychology, and other areas. For example, individuals interested in paticnt outcome with air transport versus ground transport will need to consider issues of mortality, return of function, stress of transport, and cost. These issues are of relevance to many disciplines, and each discipline brings their own perspective to the question. When considering return of function a physician may wish to examine the extent of physical immobility, whereas the nurse may be interested in the amount of home services needed at the time of discharge. Collaboration in research should strengthen the study just as collaboration in patient care improves patient outcomes. 29

\section{Resources for Nursing Research}

Adequate resources are necessary to conduct a quality research study. The resources of time, subjects, money, and research expertise are each important to the successful completion of a research project.

Transport nurses are in a unique position with regard to the requirement of time for research. Although the availability is unpredictable, most nurses do have times when they are not transporting or participating in other departmental activities. Nurses working in other aspects of patient care rarely have time away from patients during which they can plan or conduct a research study. The planning for a study can be done during "down" times for the transport nurse. In addition, data collection for many transport-related research projects can be accomplished during duty hours. Some studies may require an additional person for data collec- 


\section{Table 1}

\section{Foundation/agency}

Foundation for

Aeromedical Research

Sigma Theta Tau

National Institute

of Nursing Research

Emergency Medical Services

for Children

Robert Wood Johnson Foundation

Agency for Health Care

Policy and Research

Emergency Medicine Foundation

\section{List of Funding Resources}

Nature

Private

Private

Government

Government

Private

Government

\section{Address}

Suite 205
Phone

35 S. Kaymond Ave.

Pasadena, CA 91105

550 West North St.

Indianapolis, IN 46202

National Institutes of Health

Bethesda, MD

National Resource Center

111 Michigan Ave., NW

Washington DC 20010-2970

PO Box 2316, Princeton, NJ 08543-2316

Executive Office Center

2101 East Jefferson

Suite 602

Rockville, MD 20852

Dallas, Texas
(317) $634-8171$

(818) $793-1232$

(301) 496-0523

(202) 884-4927

(301) $591-2800$

(800) 798-1822, ext 3215 tion during transport, but this is not commonly seen.

Subjects for a research study may be much more difficult to locate than time to do the study. All but the busiest programs transport a somewhat limited number of patients from a given population. Consequently, the data collection period may be extended. However, the best approach to this problem is to extend your sample beyond a single program. This will not only increase the number of subjects available and increase the generalizability of the findings but also will increase collaboration between programs. 30

Money often is perceived as the biggest impediment to nursing research. However, sources are available for internal and/or external funding of research projects. The easiest source of funding is the nurse's own institution. If the primary needs for resources include copying, phone calls, and mailing, a program may be willing to pick up the extra charges within the established budget.

Another source of funding for a study is vendors. An individual interested in testing a specific piece of equipment is first recommended to contact a vendor and ask about the availability of equipment to be used on loan during the period of the study. Many vendors are happy to oblige because of the favorable publicity both to the program and in the form of an acknowledgment in the published findings of the study. When bor- rowing equipment the researcher must be careful not to promise to sway the results to meet the vendors needs and to state the lack of vendor involvement in research design and results when publishing the results.

If the study to be undertaken is large in scope or requires significant funding for extra personnel or equipment, additional funding may be required. The first source of funding to evaluate is that of the home institution. Many health care organizations have small research grants available for employees.

If external funding is needed, the researcher can seek either private or federal support. Private foundations and corporations often award grants to individuals doing research in their area of interest. You can contact your state or local government to ask for grant opportunities or search the World Wide Web for other sources of funds. In addition, the federal government offers several sources of research funding as do national nursing organizations. See Table 1 for a list of potential funding resources. A grant application is required for most sources of funding, but the process is not daunting if the grant is taken one step at a time. A subsequent issue of the Basics of Research series will discuss how to prepare a research grant.

Research expertise is a final resource necessary for conducting a study. Local sources should be sought first because of better availability. Larger health carc or- ganizations often have a research office through which staff can request assistance. In many, but not all cases, nurses will be available to help with the study. Other required expertise such as statistical consultants also may be available. A local college of nursing may be another source for research expertise. Faculty or doctoral students may be willing to assist with your study to gain an opportunity to teach, gain access to subjects, or become involved in a new area of research.

The National Flight Nurses Association has recognized the need for research expertise to assist individual transport programs and their staff. The research committee has compiled a list of individuals willing to help with others with their research study. Contact Cheryl Erler (address listed on title page) for further information.

Once the study is completed a final resource, an avenue for dissemination of the findings, may be needed. Research that is not disseminated to peers is a waste of resources and does not assist in knowledge development. All researchers are encouraged to submit their findings to the Annual Air Medical Transport Conference for presentation. Publication of the findings also is important. The Air Medical Journal, the Journal of Trauma, Journal of Emergency Medicine, and others directed at the various aspects of patient care during transport welcome submissions of quality research reports. A subsequent issuc of the Basics of Rescarch Series will 
discuss publication and dissemination of findings in greater detail.

\section{Research Use}

Conducting quality research is important. However, the research is of little value if it is not subsequently used by practitioners. Even if uninterested in conducting research, nurses must learn to read and use the findings of others in their practice. Research findings from a broad range of sources can be instrumental in improving patient care.

One of the barriers to research use is the lack of research findings available. This is one of the main reasons that transport nurses should be encouraged to conduct their own research. Research done in other areas may be useful, but not as directly applicable as research done in a transport environment.

Even if research related to transport is done, the findings cannot be used unless transport nurses are aware of the findings. Individuals should read not only the Air Medical Joumal but also other journals related to nursing in general, to specialty care, or to other disciplines to locate research findings relevant to transport.

Nurses often are heard to say that they do not know how to read a research report. Hopefully this series of articles will provide the skills so that all nurses can learn to read and use the research findings of others. If you are uncomfortable with interpreting a specific article, seek help from others with more experience, including individuals listed in the previous section on resources.

\section{Conclusion}

The need for research-based clinical practice has become more important as health care providers are increasingly being required to document their contribution to patient care. As stated by Brendan James during a keynote address at the Seventeenth Annual Symposium on Computer Application in Medical Care, quality is no longer only determined just by whether you live or die. Instead, quality of care is evaluated in reference to cost, total patient outcome, and patient satisfaction. 31 Transport programs can no longer rest on an assumption that, because it is high tech, air transport improves patient outcomes. Rather, the industry is under increasing pressure to document the contribution rapid transport and skilled care providers make to patient outcomes. In addition, specific interventions within the transport environment must be evaluated for their effectiveness in meeting the goal of improved patient outcomes.

Patient transport is a multidisciplinary effort, and nursing plays an important role as indicated by the fact that all but a few transport programs in the United States include a nurse as a member of the team. ${ }^{31}$ Because of this integral role in patient transport nurses must assume a larger roll in the evaluation of their practice in the transport environment. Nurses involved in air transport cannot assume that their care can be justified by researchers from other disciplines or by nurse researchers in other areas of patient care.

More transport nurses must obtain the education and experience necessary to not only use the research findings of others in an appropriate manner but also to extend nursing knowledge by independent research and contributions to multidisciplinary, collaborative research. The unique perspective of nurses and the wide range of theoretic frameworks from which they draw for their practice are powerful tools for improving the relevance and quality of health care research. Research must be recognized by transport nurses as one of the most powerful tools available for improving the quality of the lives of our patients. Nurses must continue to pursue their own programs of research as well as collaborate with others to ensure safe, cost-effective care for patients during transport.

\section{References}

1. Peterson FY, Kirchhoff KT. Analysis of the research about heparinized versus nonheparinized intravascular lines. Heart Lung 1991;20:631-42.

2. American Nurses Association. ANA Social Policy Statement. Washington, DC: American Nurses Association, 1980.

3 Bickell WH, Wail MJ, Pepe PE, et al. A comparison of immediate versus delayed fluid resuscitation for hypotensive patients with penetrating torso injury. N Eng J Med 1994;331:1105-9.

4. Schwartz RJ, Jacobs LM. Analysis and comparison of research abstracts at AAMS, 1987-1990. J Air Med Transport 1992;11:7-11.

5. Radke KJ. Age related impairment of $\mathrm{K}(+)-$ and $\mathrm{ACTH}-$ stimulated aldosterone secretion by ral adrenal capsules. An J Pliysiol 1993;264(1 pt 1):E82-9.

6. Guyton-Simmons J, Ehrmin JT. Problem solving in pain management by expert intensive care nurses. Crit Care Nurs 1994;14:37-44.

7. American Association of Critical Care Nurses. Evaluation of the effects of heparinized and nonheparinized flush solutions on the patency of arterial pressure monitoring lines: the $\mathrm{AACN}$ Thunder Project. Am J Crit Care 1993;2:3-15.

8. Baxt WG, Moody P. The impact of a rotorcraft aeromedical emergency care service on trauma mortality. JAMA 1983;249:3047-51.

9. Fischer RP, Flyn TC, Miller PW, et al. Urban helicopter response to the scene of injury. $J$ Trauma 1984;24:946-50.

10. Fox J, Menlove RL, Day S, et al. An evaluation of potential prognostic indicators in cardiac patients. J Air Med Transport 1991;10:18-30.

11. Rhee KJ, O'Malley RJ. The effect of an airway algorithm on flight nurse behavior. J Air Med Transport 1990;9:6-8.

12. Schwab CW, Peclet M, Zackowski SW, et al. The impact of an air ambulance system on an established trauma center. J Trauma 1985;25:580-5.

13. Bader GB, Terhorst M, Heilman P, et al. Characteristics of flight nursing practice. Air Med J 1995;14:214-8.

14. DeJarnette R, Ilolleran R, Von Rotz NP. et al. Pulse oximetry during helicopter transport. Air Med J 1993;1:93-9.

15. Erler CJ, Thompson C. Determining National Flight Nurses Association's research priorities: a national study. Air Med J 1995;14:16-20.

16. Fultz JH, McKee JL, Zalaznik FR, et al. Air medical transport: what the family wants to know. Air Med J 1993;12:431-5.

17. Morris M, Kinkade S. The effect of capnometry on manual ventilation technique. Air Med J 14:79-82.

18. O'Malley RJ, Watson-Hopkins M. Monitoring the appropriateness of air medical transports. Air Med J 1994;13:323-5. 
19. Perez L, Winchell JT, King L. Use of an air medical helicopter in a trauma prevention program. Air Med J 1994:13:247-50.

20. Ryan R, Studebaker BL, Brennan GD. Helmet use: What message are we sending to jatients? Air Med J 1994;13:346-8.

21. Thompson $\mathrm{CB}$, Balasz $\mathrm{K}$, Goltermann J, et al. Intubation quality assurance thresholds. Air Med J 1995;14:55-60

22. Travers DA. Means I. Riordan I. Determining appropriate use of an air medical program. J Air Med Transport 1989;8:7-9.

23. Wraa CE, O'Malley RJ. Flight nurse physical re- quirements. J Air Med Transport 1992;11:17-20

24. CURN Project Michigan Nurses Association Structured preoperative teaching. New York: Grune \& Stratton, 1981.

25. Johnson JE. Coping with elective surgery. In: Werley HH, Fitzpatrick JJ, editors. Annual Review of Nursing Research. New York: Springer, 1984;2:107-32

26. Johnson JE, Nail LM, Lauver D, et al. Reducing the negative impact of radiation therapy on functional status. Cancer 1988;61:46-51.

27. Polit DF, Hungler BP. Nursing research: principles and methods. 5th ed. Philadelphia: Lippin- cott, 1995.

28. Boswell WC, McElveen N, Sharp M, et al. Analysis of prehospital pediatric and adult intubation. Air Med J 1995;14:125-8.

29. Baggs JG, Schmitt MH. Intensive care decisions about level of aggressiveness of care. Res Nurs Health 1995; 18:345-55.

30. Thompson CB, Panacek EA. Basics of research (part 4): research study design (part 2). Air Med J 1995;14:222-31.

31. Cady G. 1994 Air Medical Program Survey. Air Med J 1994;13:353-8. 